\title{
Work in Progress: The Impact of a Self-Guided Assessment Tool on Success and Retention of At-Risk Students
}

\section{Ms. Julie Chiki, Ohio University}

Julie Chiki is a student success advisor for the Russ College of Engineering and Technology at Ohio University. She holds a master's degree in college student personnel from Ohio University and a bachelor's degree in journalism from Northwestern University.

\section{Braden Vale Jay Robinson, Ohio University}

Braden Robinson is a current graduate student in the College Student Personnel Administration M.Ed. program at Ohio University. He served as a Practicum Student for the Russ College of Engineering and Technology for the Spring Semester 2017. 


\title{
Work in Progress: The Impact of a Self-Guided Assessment Tool on Success and Retention of At-Risk Students
}

\begin{abstract}
This work-in-progress paper will describe an online self-guided goal-setting tool designed to help students retaking courses without a significant increase in advisor workload. The aim is to reduce the number of students requiring a third attempt of a course, thereby decreasing time to graduation and increasing retention, as emerging research on the "murky middle" has shown that attrition is driven by the number of failed courses rather than overall decline in GPA [1].
\end{abstract}

Introduction

Ohio University is a public, residential college located in the Midwest with approximately 18,000 undergraduate students, including 1,800 undergraduates in the Russ College of Engineering and Technology. At our institution, students must pass every course required for their major in three attempts or fewer, often with a grade of $\mathrm{C}$ or better, or they are dismissed from the major. To reduce the number of students being dismissed, we created a self-assessment and contract based on appreciative and proactive advising for use during individual meetings with students on their third attempt of a class. Appreciative advising uses a positive approach to help students identify their strengths and co-create a plan to reach their goals using those strengths [2].

The initial outreach saw an improvement in the passing rate of third attempt classes from 46 percent in the semester prior to the intervention, to 67 percent after two semesters, and is consistent with findings from Meyer and Marx [3], who determined that students lost confidence after not being successful in a course, which manifested in a lack of effort in future courses. They suggested that additional outreach could positively impact retention.

While this first outreach did improve the passing rates for students on their third attempt of a course, it did not reduce the total number of students requiring a third attempt. This is problematic because as students continue to experience failure, their time to graduation increases, motivation decreases, and students sometimes try to increase their course load to "catch up," often compounding the problem.

Compared to the approximately 70 students who require a third attempt at our institution each term, there are more than 300 students who retake a course for the first time each semester. Because meeting individually with that many students was not feasible, we re-envisioned the original self-assessment and contract as an online tool that would provide similar resources to a much larger number of students.

Our survey aims to remind students of their reasons for pursuing engineering and the strengths they can draw on to be successful, along with helping them set goals to increase their motivation. This aligns with a recent study that reaffirmed that self-efficacy, or students' beliefs that they could be successful, was positively related to mastery goals and students' intentions to persist, which was most predictive of future success [4]. 
Methods

We built our online assessment using the cloud-based survey software Qualtrics. Students are asked to identify their overall purpose for attending college, their academic strengths, reasons for their academic difficulties, and then asked to set two goals for the semester addressing those difficulties. When students are asked to complete the assessment, they are also added to a "Russ College Retakes" site on our learning management system with links to university support resources and study skills.

Two weeks after completing the Qualtrics assessment, students are automatically reminded of their goals via email and asked to re-assess their progress. If they would like additional help, they are invited to schedule an advising meeting. In the spring, with the help of a part-time graduate assistant, we were able to send weekly "nudges" - short, descriptive emails to keep students motivated and updated on important information and deadlines [5]. Emails often included a picture and 2-3 sentences about a resource or information related to the time of the semester (Table 1). Messages were intentionally kept short to engage students without overwhelming them. These emails were often linked to the "Russ College Retakes" site to drive traffic to existing resources.

Table 1: Schedule of Survey Distributions and "Nudge" Emails, Spring 2017

\begin{tabular}{|l|l|l|}
\hline Date & $\begin{array}{l}\text { Week of } \\
\text { Semester }\end{array}$ & Topic \\
\hline $1 / 16$ & Week 2 & Survey Email \#1 \\
\hline $1 / 19$ & & Introduction, Drop/Add Reminder \\
\hline $1 / 25$ & Week 3 & Survey Reminder \#1 \\
\hline $1 / 26$ & & Resources - Tutoring and Office Hours \\
\hline $2 / 2$ & Week 4 & Goal-Setting (Aim higher than a C) \\
\hline $2 / 2$ & & Survey Reminder \#2 \\
\hline $2 / 9$ & Week 5 & Exam Preparation \\
\hline $2 / 16$ & Week 6 & Campus Emergency - University Closed \\
\hline $2 / 23$ & Week 7 & Midterm Check-in/Time Management \\
\hline $3 / 2$ & Week 8 & Safe Spring Break/Self Care \\
\hline $3 / 9$ & & Spring Break - No Email \\
\hline $3 / 13$ & Week 9 & Survey Reminder \#3 (In conjunction with mid-term grade reports) \\
\hline $3 / 16$ & & Drop Deadline Reminder \\
\hline $3 / 23$ & Week 10 & Have you scheduled an advising meeting? \\
\hline $3 / 30$ & Week 11 & Stress Management \\
\hline $4 / 6$ & Week 12 & Compiling Notes and Study Materials \\
\hline $4 / 13$ & Week 13 & Final Exam Study Tools \\
\hline $4 / 20$ & Week 14 & Finals Week Motivation \\
\hline
\end{tabular}




\section{Survey Development}

The online assessment was piloted in the summer of 2016. The survey was sent to 161 students, with 19 students $(11.8 \%)$ beginning the survey but only 11 (6.8\%) completing it. Based on those results, the assessment was modified to include only one page, as most unfinished surveys were abandoned at the page break. This eliminated the ability to tailor the survey based on students' initial responses, but resulted in higher completion rates.

For fall semester 2016, we sent the assessment to 350 students, including one reminder email to those who had not yet completed the survey, and received a total of 54 responses $(15.4 \%$ response rate). So far this spring, 72 out of 412 students have completed the survey $(17.5 \%$ response rate). We sent three scheduled reminder emails to encourage higher participation, including a final reminder after midterm grade reports came out.

In the summer and fall versions of the assessment, students were able to select from suggested responses. For example, suggested goals included attending all classes, using tutoring or office hours regularly, setting a consistent bedtime, reducing work or extracurricular hours, or scheduling counseling appointments, with links to relevant resources embedded in the text of the goals. In spring, we created two separate surveys: one that required students to write original responses to each question, and the other that allowed students to select from suggested responses randomly displayed, including an "other" box where they could fill in their own responses. We hoped to see if this would encourage more critical thinking in the reflection process.

Students were randomly assigned to receive one of the two surveys, with equal numbers assigned from each class rank (first-year, sophomore, junior, senior). Although we gained helpful insights through the open-ended version of the survey (described in the results section), only $45 \%$ of students who started the open-ended survey completed it, compared to $79 \%$ for the multiple choice survey. We suspect this low completion rate is due to the length of the survey.

Preliminary Results

Results from the survey enabled us to measure the effectiveness in reducing the number of students requiring a third attempt of a class and helped us gather information from students about their potential needs and ways to send individualized resources.

Using fall semester grades, we compared the success of students who completed the survey with those who did not and found that $77.2 \%$ of students completing the survey passed the courses they were retaking with a satisfactory grade, compared to $72.3 \%$ for those who did not. The passing rate for the entire group was $73 \%$. When students who were on their third attempt of a course were removed from the analysis, those numbers jumped to $83.7 \%$ passing rate for those who completed the survey compared to $78.0 \%$ passing rate for those who did not, and an overall passing rate of $78.9 \%$.

One clear confounding variable is that students who are motivated to complete the survey are also likely to be more motivated to improve their academic performance. To address this issue, 
we are working with the registrar's office to compare the passing rate to the previous fall semester, when no retake intervention was in place.

Results from individual survey questions on the fall and spring surveys showed several common themes. Students were asked why they were pursuing their current major to remind them of their motivation for persisting (Table 2), and the most popular responses were "I want to get a good job" (75\%) and "I enjoy the subject" (53.6\%).

Table 2: Responses to "Why did you choose to attend Ohio University and pursue your current major?"

\begin{tabular}{|lcc|}
\hline Answer & $\begin{array}{c}\text { \% of } \\
\text { Respondents } \\
\text { Fall 2016 }\end{array}$ & $\begin{array}{c}\text { \% of } \\
\text { Respondents } \\
\text { Spring 2017 }\end{array}$ \\
\hline I want to get a good job & $75.00 \%$ & $60.87 \%$ \\
\hline I enjoy the subject & $53.60 \%$ & $58.70 \%$ \\
\hline I want to make a difference in the world & $48.20 \%$ & $52.17 \%$ \\
\hline Going to college was the next logical step & $46.40 \%$ & $34.78 \%$ \\
\hline I've always been good at math and science & $41.10 \%$ & $41.30 \%$ \\
\hline Someone suggested it to me & $16.10 \%$ & $10.87 \%$ \\
Other (Qualitative) & $5.40 \%$ & $2.17 \%$ \\
\hline I'm not sure & $0.00 \%$ & $0.00 \%$ \\
\hline
\end{tabular}

In keeping with the appreciative model, students were also asked to reflect on their personal strengths before considering their academic failures. When asked what kept them from reaching their full potential in the previous semester (Table 3), students most commonly selected "anxiety, depression, or stress" (58.9\%) and "poor time management/procrastination" (55.4\%). In the spring, students chose similar reasons for the poor performance. "Anxiety, depression, or stress" remained the top response $(58.7 \%)$, and test anxiety moved up the list to $52.2 \%$.

Students were also asked to choose at least two goals to improve their academic performance in the current semester (Table 4). The top responses included "I will read every course syllabus and add all test dates/due dates in my planner or semester calendar" $(73.2 \%)$ and "I will attend all class sessions except in case of emergency or pre-arranged absence" (69.6\%).

Similar themes also appeared in the open-ended version of the spring retake assessment. Almost all students who completed the assessment noted getting a good job and enjoying the subject as common reasons for pursuing their major. In terms of barriers to success, many students still listed responses relating to anxiety, depression, or stress, and a much more prevalent theme of not taking enough personal responsibility, citing causes such as not taking sufficient notes, not being fully engaged in class, or falling behind for social reasons. Goals and aspirations were more individualized to the students' goals. 
Table 3: Responses to "What factors have kept you from using your strengths and reaching your full academic potential? Choose all that apply."

\begin{tabular}{|lcc|}
\hline Answer & $\begin{array}{c}\text { \% of } \\
\text { Respondents } \\
\text { Fall 2016 }\end{array}$ & $\begin{array}{c}\text { \% of } \\
\text { Respondents } \\
\text { Spring 2017 }\end{array}$ \\
\hline Anxiety, depression or stress & $58.93 \%$ & $58.70 \%$ \\
\hline Poor time management/procrastination & $55.36 \%$ & $43.48 \%$ \\
\hline Lack of motivation & $42.86 \%$ & $32.61 \%$ \\
\hline Lack of sleep & $35.71 \%$ & $47.83 \%$ \\
\hline Difficult course material & $33.93 \%$ & $43.48 \%$ \\
\hline Test anxiety & $33.93 \%$ & $52.17 \%$ \\
\hline Lack of study skills & $33.93 \%$ & $32.61 \%$ \\
\hline Adjustment to college & $30.36 \%$ & $23.91 \%$ \\
\hline Financial issues & $28.57 \%$ & $15.22 \%$ \\
\hline Heavy course load & $26.79 \%$ & $47.83 \%$ \\
\hline Unhappy with instructor & $21.43 \%$ & $28.26 \%$ \\
\hline Unsure of major & $17.86 \%$ & $8.70 \%$ \\
\hline No clear career goals or plans & $16.07 \%$ & $8.70 \%$ \\
\hline Poor class attendance & $16.07 \%$ & $19.57 \%$ \\
\hline Housing/roommate issues & $16.07 \%$ & $15.22 \%$ \\
\hline Trouble making friends & $16.07 \%$ & $13.04 \%$ \\
\hline Homesickness & $12.50 \%$ & $6.52 \%$ \\
\hline Working too many hours & $12.50 \%$ & $17.39 \%$ \\
\hline Family issues & $12.50 \%$ & $32.61 \%$ \\
\hline Overinvolved in activities & $10.71 \%$ & $15.22 \%$ \\
\hline Injury or illness & $8.93 \%$ & $8.70 \%$ \\
\hline Possible learning disability & $5.36 \%$ & $2.17 \%$ \\
\hline Use of alcohol or other substances & $3.57 \%$ & $2.17 \%$ \\
\hline & & \\
\hline
\end{tabular}

To analyze the impact of the "nudge" emails, we tracked the number of hours students spent on the "Russ College Retakes" site. In the fall semester of 2016, students were notified about the resource by email at the beginning of the semester, and they logged a cumulative 5.44 hours on the site. In the spring semester 2017, when students were sent weekly emails linking to resources on the site, that number increased to 18.42 hours. More than half of these hours (10.72) fell on a Thursday, when the nudge emails were sent. While not definitive, this is an indicator that at least a portion of students were also reading the nudge emails on a regular basis and accessing the resources provided. 
Table 4: Responses to: "To improve your performance next semester, you will need to try new or different strategies. Choose at least two goals below, or write in your own."

\begin{tabular}{lcc}
\hline Answer & $\begin{array}{c}\text { \% of } \\
\text { Respondents } \\
\text { Fall 2016 }\end{array}$ & $\begin{array}{c}\text { \% of } \\
\text { Respondents } \\
\text { Spring 2017 }\end{array}$ \\
\hline $\begin{array}{l}\text { Read every course syllabus and add all test dates/due dates in my } \\
\text { planner or semester calendar }\end{array}$ & $73.21 \%$ & $43.48 \%$ \\
$\begin{array}{l}\text { Attend all class sessions except in case of emergency or pre-arranged } \\
\text { absence }\end{array}$ & $69.64 \%$ & $56.52 \%$ \\
$\begin{array}{l}\text { Create a study schedule that includes a minimum of } 2 \text { hours of } \\
\text { study/homework time per credit hour each week }\end{array}$ & $41.07 \%$ & $43.48 \%$ \\
$\begin{array}{l}\text { Set a bedtime on weeknights to ensure I get enough sleep and make it to } \\
\text { class }\end{array}$ & $37.50 \%$ & $43.48 \%$ \\
$\begin{array}{l}\text { Attend office hours once per week with specific questions about } \\
\text { homework or lecture notes }\end{array}$ & $32.14 \%$ & $30.43 \%$ \\
\hline $\begin{array}{l}\text { Join a student organization related to my career goals or to meet other } \\
\text { students with similar interests to mine }\end{array}$ & $28.57 \%$ & $19.57 \%$ \\
\hline $\begin{array}{l}\text { Attend all Supplemental Instruction (SI) sessions available for the } \\
\text { course }\end{array}$ & $19.64 \%$ & $28.26 \%$ \\
$\begin{array}{l}\text { Cut back on work or extracurricular involvement } \\
\text { Visit financial aid for additional options to pay for school }\end{array}$ & $16.07 \%$ & $34.78 \%$ \\
\hline $\begin{array}{l}\text { Sign up for tutoring at least once per week (tutoring is free for many } \\
\text { math and science courses) }\end{array}$ & $12.50 \%$ & $6.52 \%$ \\
\hline $\begin{array}{l}\text { Meet with a counselor to discuss personal issues affecting my academic } \\
\text { performance }\end{array}$ & $10.71 \%$ & $19.57 \%$ \\
\hline $\begin{array}{l}\text { Meet with the Student Success Advisor to explore other major options } \\
\text { Visit Student Accessibility Services to learn about accommodations for } \\
\text { learning disabilities, chronic illnesses or injuries }\end{array}$ & $10.71 \%$ & $17.39 \%$ \\
\hline \begin{tabular}{l} 
Schedule a meeting with my advisor to discuss reducing my course load \\
\hline
\end{tabular} & $8.93 \%$ & $4.35 \%$ \\
\hline
\end{tabular}

\section{Future Plans}

Development of the assessment and strategies to encourage student participation has been the main focus of our efforts this year. Once grades become available for spring semester 2017, we plan to compare the success rate of course retakes in 2015-16 prior to the implementation of this program, to 2016-17, using chi square statistical analysis.

We also plan to develop more individualized interventions based on the results we have collected so far. For example, one result of our data collection has been the frequency of anxiety, depression, or stress cited as a reason for students' failure. The Qualtrics survey platform allows for targeted responses based on individual answers, so we could send counseling resources and tips for stress management directly to those students who reported a need. The nature of the question limits our ability to tell how many of these students have mental health concerns versus stress caused by heavy course loads, poor study skills and/or limited time. We will explore rewording this question on future assessments to get more precise data.

More generally, we will look for more ways to engage students once they have completed the retake assessment, not only with automated follow-up emails, but also with examination of our 
"nudge" emails and their effectiveness in encouraging students to engage with the assessment and learning management site.

The retake assessment is not required for students to take at this point. If additional data collection shows an increasing effectiveness to the survey, we may explore using registration holds to require completion of the assessment and/or weekly reminders until the assessment is completed. In addition, other university departments have shown interest in adapting the retake assessment, which would allow for a larger sample of data collection and analysis.

Discussion and Conclusion

Although initial impact of the course retake assessment appears to be small, we believe it holds promise as a tool that allows a personalized student experience with little ongoing attention required from advisors once configured. It is not meant to be a replacement to individual advising and support, but as a supplement that allows advisors to focus on students with the highest risk while still supporting those struggling to make efficient progress through the curriculum. Our hope is that as the rate of student engagement with the assessment improves, so will its impact on students.

References

[1] Tyson, C. (2014, September 10). The 'murky middle.' Inside Higher Ed. Retrieved from https://www.insidehighered.com/news/2014/09/10/maximize-graduation-rates-collegesshould-focus-middle-range-students-research-shows

[2] Bloom, J. L., Hutson, B. L., \& He, Y. (2008). The appreciative advising revolution. Champaign, IL: Stipes Publishing.

[3] Meyer, M., \& Marx, S. (2014). Engineering dropouts: A qualitative examination of why undergraduates leave engineering. Journal of Engineering Education, 103(4), 525-548.

[4] Mamaril, N. A., Usher, E. L., Li, C. R., Economy, D. R. \& Kennedy, M. S. (2016). Measuring undergraduate students' engineering self-efficacy: A validation study. Journal of Engineering Education, 105(2), 366-395.

[5] Thaler, R. \& Sunstein, C. (2008). Nudge: Improving decisions about health, wealth and happiness. New Haven, CT: Yale University Press. 